\title{
A Raman Spectroscopic Study of the Interaction Between Nucleotides and the DNA Binding Protein gp32 of Bacteriophage T4
}

\author{
C. OTTO, F. F. M. DE MUL, and J. GREVE, University of Twente, \\ Department of Applied Physics, P.O. Box 217, 7500 AE Enschede, \\ The Netherlands
}

\begin{abstract}
Synopsis
Raman spectra of the bacteriophage $\mathrm{T} 4$ denaturing protein gp32, its complex with the polynucleotides poly $(\mathrm{rA})$, poly $(\mathrm{dA})$, poly $(\mathrm{d} T)$, poly $(\mathrm{rU})$, and poly $(\mathrm{rC})$, and with the oligonucleotides $(\mathrm{dA})_{8}$ and $(\mathrm{dA})_{2}$, were recorded and interpreted. According to an analysis of the gp32 spectra with the reference intensity profiles of Alix and co-workers [M. Berjot, L. Marx, and A. J. P. Alix (1985) J. Ramanspectrosc., submitted; A. J. P. Alix, M. Berjot, and J. Marx (1985) in Spectroscopy of Biological Molecules, A. J. P. Alix, L. Bernard, and M. Manfait, Eds., pp. 149-154], 1 gp32 contains $\approx 45 \%$ helix, $\approx 40 \% \beta$-sheet, and $15 \%$ undefined structure. Aggregation of gp 32 at concentrations higher than $40 \mathrm{mg} / \mathrm{mL}$ leads to a coordination of the phenolic $\mathrm{OH}$ groups of 4-6 tyrosines and of all the sulfhydryl ( $\mathrm{SH}$ ) groups present in the protein with the $\mathrm{COO}^{-}$groups of protein. The latter coordination persists even at concentrations as low as $1 \mathrm{mg} / \mathrm{mL}$. In polynucleotide-protein complexes the nucleotide shields the 4-6 tyrosine residues from coordination by the $\mathrm{COO}^{-}$groups even at high protein concentration. The presence of the nucleotide causes no shielding of the SH groups. With Raman difference spectroscopy it is shown that binding of the protein to a single-stranded nucleotide involves both tyrosine and trytophan residues. A change in the secondary structure of the protein upon binding is observed. In the complex, gp32 contains more $\beta$-sheet structure than when uncomplexed. A comparison of the spectra of complexed poly $(\mathrm{rA})$ and poly $(\mathrm{dA})$ with the spectra of their solution conformations at $15^{\circ} \mathrm{C}$ reveals that in both polynucleotides the phosphodiester vibration changes upon complex formation in the same way as upon a transition from a regular to a more disordered conformation. Distortion of the phosphate-sugar-base conformation occurs upon complex formation, so that the spectra of poly $(\mathrm{rA})$ and poly $(\mathrm{dA})$ are more alike in the complex than they are in the free polynucleotides. The decrease in intensity of the Raman bands at $1304 \mathrm{~cm}^{-1}$ in poly(rA), at 1230 $\mathrm{cm}^{-1}$ in poly(rU), and at 1240 and $1378 \mathrm{~cm}^{-1}$ of poly(dT) may be indicative of increased stacking interactions in the complex. No influence of the nucleotide chain length upon the Raman spectrum of gp $32^{2}$ in the complex was detected. Both the nucleotide lines and the protein lines in the spectrum of a complex are identical in poly $(\mathrm{dA})$ and $(\mathrm{dA})_{8}$.
\end{abstract}

\section{INTRODUCTION}

Helix-destabilizing proteins lower the melting temperature of doublestranded polynucleotides. This results from the strong binding to singlestranded polynucleotides combined with a weak binding to double-stranded polynucleotides. ${ }^{1}$ Coded by gene 32 of bacteriophage $\mathrm{T} 4, \mathrm{gp} 32^{2}$ is one of these helix-destabilizing proteins. It is produced in large quantities during phageDNA replication. It plays a role in the protection of single-stranded DNA from nuclease attack and keeps the single-stranded DNA in a conformation 
suited for the proper functioning of the other proteins active during the replication.

A positive cooperative ${ }^{3}$ interaction between gp32 molecules assures complete saturation of the polynucleotide with protein under low salt conditions. ${ }^{4}$ An oligonucleotide binding mode can be distinguished from a polynucleotide binding mode by a decreased salt dependence of the effective binding constant for oligonucleotides. ${ }^{4}$ This fact, together with an increased mobility of the C-terminal end ${ }^{5}$ of the protein upon complex formation, indicates a change of the protein conformation in both the poly- and oligonucleotide binding mode. ${ }^{4-6}$

The gp32 shows a strong tendency to aggregate even at low protein concentrations. It has been suggested ${ }^{7}$ that more than one type of protein-protein interaction plays a role leading to aggregates of unlimited size.

Several models have been suggested ${ }^{4,8-12}$ for the conformation of the gp32-polynucleotide complex. An electron microscopic study ${ }^{10}$ and a hydrodynamic study ${ }^{9}$ have established a $50 \%$ increase in phosphate-phosphate distance of the polynucleotide in the complex. No agreement exists about the number of nucleotide units covered by one protein molecule. Estimates range from five ${ }^{11}$ to eight $^{13}$ nucleotides per protein molecule. Recent studies have suggested that gp32 may cover even 10 nucleotides. ${ }^{14,15}$ The occurrence of a hyperchromic effect in the polynucleotide absorption spectrum of poly(rA) upon gp32 binding has been interpreted ${ }^{16}$ as due to an unstacking of the base residues. The large changes ${ }^{9,16}$ in $\mathrm{CD}$ spectra can also be explained as a weakening of the coupling of the transition moments ${ }^{16}$ of the base molecules. From a combination of hydrodynamic studies and absorption and CD spectroscopy, Scheerhagen ${ }^{14}$ has conjectured a detailed model, in which it is suggested that the gp32-poly(rA) complex consists of a helix with a diameter of $1.4 \mathrm{~nm}, 24$ bases per turn, and a pitch of $14.4 \mathrm{~nm}$. This helix is wound into a superhelix with 40 bases per superturn, a diameter of $5.0 \mathrm{~nm}$, and a pitch of $18.4 \mathrm{~nm}$.

The gp32 is a globular protein that consists of one strand of 301 amino acids, the composition and sequence of which are known., 6,17 The very large amount of acidic amino acids (about $25-30 \%$ is present as aspartic and glutamic acid residues) results in an isoelectric point at $\mathrm{pH} 5 .^{6}$ Among the other residues are 18 phenylalanines, 5 tryptophans, and 8 tyrosines.

The presence of a regular array of tyrosine residues has been demonstrated and may be of importance for nucleotide binding. ${ }^{17} \mathrm{~A} \mathrm{nmr}$ study ${ }^{18}$ of the nucleotide binding part of the protein complexed with oligonucleotides of varying length has shown that the proton resonances of one phenylalanine, one tryptophan, and five tyrosine residues shift upon nucleotide binding. This provided evidence that some of the aromatic residues are directly involved in complex formation. The importance of aromatic residues for polynucleotide binding also has become clear from chemical studies. After modification of tryptophan ${ }^{19}$ or tyrosine, ${ }^{12}$ polynucleotide binding was inhibited whereas no changes in gp32 conformation could be discovered.

The effective binding constant of gp32 to polynucleotides is both nucleotide and sugar moiety dependent. It has been reported ${ }^{13}$ that, at physiological salt concentrations, poly(dT) binds about seven times stronger than poly $(\mathrm{dA})$ and 
that poly $(\mathrm{dA})$ binds about ten times stronger than poly(rA). The reason for differences in binding strength is unknown.

From CD studies it is clear ${ }^{14}$ that the bases of the polynucleotide in a poly(rA)-gp32 complex are arranged in a different way than in a poly(dA)-gp32 complex. It is not known whether the protein conformation in both complexes is the same.

It is well known that Raman spectroscopy can give information about the conformation and interaction of polynucleotides and proteins. An advantage of Raman spectroscopy is that, in principle, information about both the protein and the nucleotide part of a complex is obtained. As the nucleotide and the aromatic amino acid residues have clearly recognizable vibrations, it may be expected that information about the role of these residues in complex formation will be obtained. Data about overall conformational changes may also be deduced from the phosphate backbone and amide vibrations.

In this paper we present the results of a Raman spectroscopic study of the complex formation between gp32 and poly $(\mathrm{rA})$, poly $(\mathrm{rC})$, poly $(\mathrm{rU})$, poly $(\mathrm{dA})$, $\operatorname{poly}\left(\mathrm{d}^{\prime} \mathrm{T}\right),(\mathrm{dA})_{8}$, and $(\mathrm{dA})_{2}$.

\section{MATERIALS AND METHODS}

\section{The gp32}

The gp32 was obtained as a generous gift from Dr. Blok of the Free University in Amsterdam. It was prepared and purified as in Ref. 6, with a few modifications as described in Ref. 14 . The protein was stored at $-20^{\circ} \mathrm{C}$ in a buffer containing $20 \mathrm{~m} M$ Tris HCL, pH 8, $1 \mathrm{~m} M \mathrm{Na}_{2}$ EDTA, $1 \mathrm{~m} M$ 2-mercaptoethanol, $50 \%$ glycerol, and $0.1 M \mathrm{NaCl}$. The concentration of the protein in the storage buffer was $4-9 \mathrm{mg} / \mathrm{mL}$. Before measurements, the protein was transferred to a buffer containing $10 \mathrm{~m} M$ sodium cacodylate and $0.1 M \mathrm{NaCl}$ with $\mathrm{pH} 7.5$, through dialysis during $24 \mathrm{~h}$ in Sartorius microcollodion bags. The volume of the protein solution and the protein concentration was then measured using an extinction coefficient of $\epsilon=36900 M^{-1} \mathrm{~cm}^{-1}$ at $280 \mathrm{~nm}$ and a molecular weight of 33487 atomic mass units. Because the desired protein concentration in the measuring buffer was $10 \mathrm{mg} / \mathrm{mL}$, it was always necessary to concentrate the protein after the first dialysis. A second dialysis against the appropriately diluted cacodylate/ $\mathrm{NaCl}$ buffer assured that, after concentration of the sample under a gentle stream of filtered (Millipore, $0.2 \mu \mathrm{m}) \mathrm{N}_{2}$ gas, the composition of the solution was as desired. In the case of measurements of deuterated samples, the same procedure was used. In all experiments a salt concentration of $100 \mathrm{~m} M$ was chosen such that stoichiometric binding of the poly(oligo)nucleotides takes place. ${ }^{4}$ All spectra were recorded at $15^{\circ} \mathrm{C}$ except for the spectra at high protein concentration, which were measured at ambient temperature $\left(\approx 23^{\circ} \mathrm{C}\right)$.

\section{Nucleotides}

The nucleotides were obtained from Sigma $[\operatorname{poly}(\mathrm{rA})]$ and PL Biochemicals $\left[\operatorname{poly}(\mathrm{rU}), \operatorname{poly}(\mathrm{rC}), \operatorname{poly}(\mathrm{dA})\right.$, poly $(\mathrm{d} T),(\mathrm{dA})_{8}$, and $\left.(\mathrm{dA})_{2}\right]$. After dissolution, the polynucleotides were dialyzed against the same (measuring) buffer as the protein. The oligonucleotides were used without further purification. The 
extinction coefficients used are poly $(\mathrm{rA})-\epsilon=10000 M^{-1} \mathrm{~cm}^{-1}$ at $257 \mathrm{~nm}$; poly $(\mathrm{dA})-\epsilon=9100 M^{-1} \mathrm{~cm}^{-1}$ at $260 \mathrm{~nm}$; poly $(\mathrm{dT})-\epsilon=8100 M^{-1} \mathrm{~cm}^{-1}$ at $260 \mathrm{~nm} ;(\mathrm{dA})_{8}-\epsilon=9980 M^{-1} \mathrm{~cm}^{-1}$ at $260 \mathrm{~nm} ;(\mathrm{dA})_{2}-\epsilon=12450 M^{-1} \mathrm{~cm}^{-1}$ at $260 \mathrm{~nm}$; poly $(\mathrm{rU})-\epsilon=9430 \mathrm{M}^{-1} \mathrm{~cm}^{-1}$ at $261 \mathrm{~nm}$; and poly $(\mathrm{rC})-\epsilon=7150 M^{-1}$ $\mathrm{cm}^{-1}$ at $269 \mathrm{~nm}$. Spectra of the nucleotides were recorded using the previously mentioned buffer except in the case of poly $(\mathrm{rC})$, which was measured at $\mathrm{pH} 8.8$ to prevent formation of double-stranded poly $(\mathrm{rC}){ }^{20,21}$ These spectra were also recorded at $15^{\circ} \mathrm{C}$ unless otherwise indicated.

The protein/polynucleotide ratio used for the formation of the complexes was one protein to 7 nucleotides.

\section{Raman Spectroscopy}

The Raman spectrometer consisted of a Jobin-Yvon HG2S monochromator and a Coherent Argon-ion laser operating at $514.5 \mathrm{~nm}$. The photomultiplier was a Hamamatsu R 943-02. The 632.8-nm line of the He-Ne laser and the $514.5-\mathrm{nm}$ line were used for wavelength calibration.

An LSI-11 computer controlled the measurements. For optimization of the signal intensity, backscatter optics and dual beam passage were used. For samples containing a low protein concentration $(10 \mathrm{mg} / \mathrm{mL})$, a high light power of $900 \mathrm{~mW}$ was used. No deterioration of the protein occurred as was checked by comparison of spectra from multirun experiments. Slit widths were chosen to give a spectral resolution of $3.2 \mathrm{~cm}^{-1}$. The recorded line maxima had an accuracy of $\pm 2 \mathrm{~cm}^{-1}$.

\section{Treatment of the Spectral Data}

Two band positions at 1004 and $1447 \mathrm{~cm}^{-1}$ have been considered as internal intensity references. The $\mathrm{CH}_{2}$-bending mode at $1447 \mathrm{~cm}^{-1}$ has been used in previous studies ${ }^{22,23}$ as an intensity reference. Both the 1004- and $1447-\mathrm{cm}^{-1}$ positions have been used to obtain difference spectra in the following way:

$$
\{\text { difference }\}=\{\text { complex }\}-\{\text { free polynucleotide }+ \text { free protein }\}
$$

The complex spectra and the free protein spectrum used to calculate the difference spectrum were all obtained with low protein concentrations $(\approx 10$ $\mathrm{mg} / \mathrm{mL}$ ). In Fig. 1 a comparison is made between Raman difference spectra using the $1447-\mathrm{cm}^{-1}$ band [Fig. 1(A)] and the 1004- $\mathrm{cm}^{-1}$ band [Fig. 1(B)] as a standard. Corresponding positive or negative contributions are indicated with a double arrow. These features will be discussed. Additional positive protein contributions indicated with a single arrow are observed in the difference spectrum for which the $1447-\mathrm{cm}^{-1}$ band was used as an intensity reference. We have concluded that the coefficient used for protein subtraction has been too small in that case and therefore prefer to use the $1004-\mathrm{cm}^{-1}$ band as an internal intensity reference. Another rationale for this choice is that the intensity of this line and its ratio to the intensity of the $1032-\mathrm{cm}^{-1}$ line of phenylalanine is the same in the free amino acid in solution, and in the protein and protein-nucleic acid complexes. The consequence of this choice is 


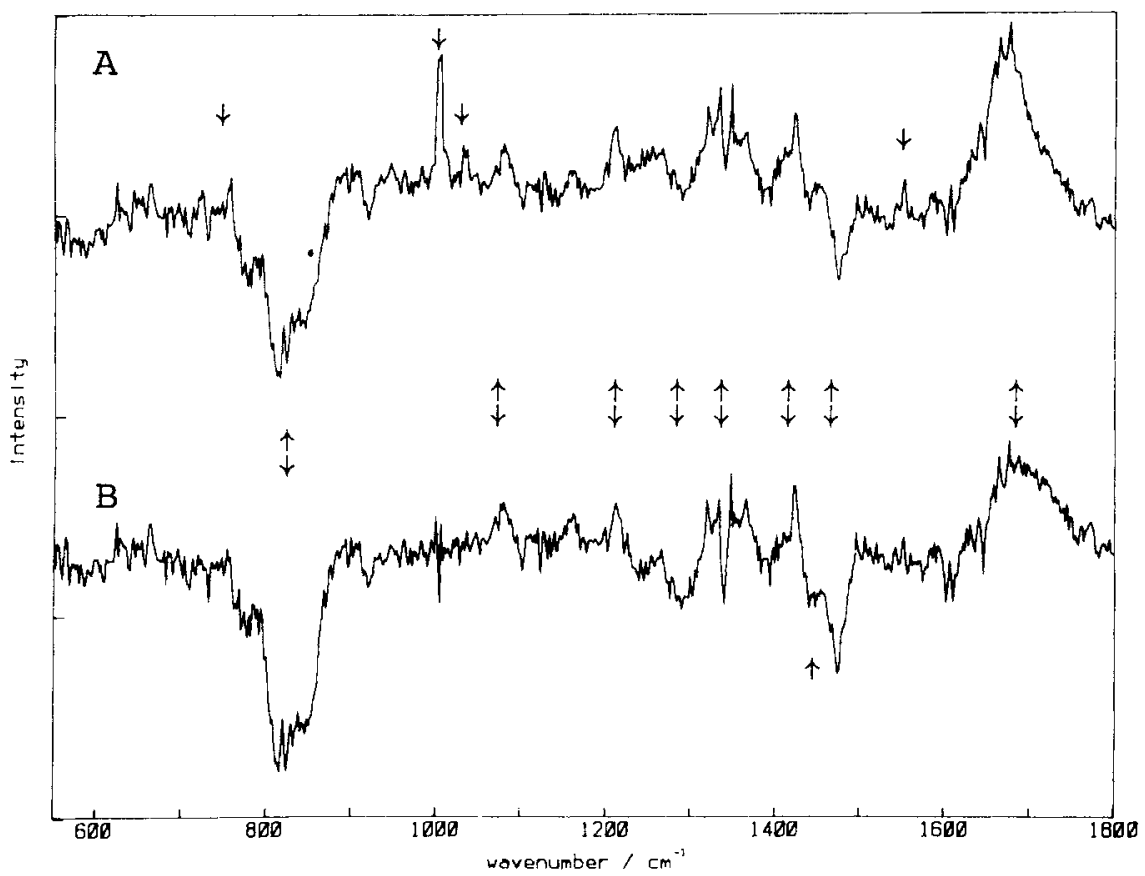

Fig. 1. The effect of the choice of the intensity reference upon difference spectra is illustrated. In $\mathrm{A}$, the band at $1447 \mathrm{~cm}^{-1}$ is used. Positive protein contributions remain at $756,1004,1032$, and $1550 \mathrm{~cm}^{-1}$; these contributions disappear when the $1004-\mathrm{cm}^{-1}$ band is used (B). Other contributions to the difference spectra (indicated with a double arrow) are independent of the choice of either of these bands as an intensity reference and are discussed in the discussion section. It is concluded that in the study of the Raman spectrum of gp32 the band at $1004 \mathrm{~cm}^{-1}$ is a more reliable standard than the band at $1447 \mathrm{~cm}^{-1}$.

that a negative contribution arises in the difference spectrum at $1447 \mathrm{~cm}^{-1}$ [Fig. 1(B)].

All the changes in the protein and in the nucleotide resulting from complex formation are represented in the difference spectrum. The amount of polynucleotide used in calculation of the difference spectrum was obtained from the chosen protein to polynucleotide ratio. This procedure was checked with samples that contained adenine, using the $1576-\mathrm{cm}^{-1}$ line as an internal intensity reference, ${ }^{24}$ and was proved satisfactory.

\section{Interpretation of the Amide I Spectral Region}

A curve-fitting procedure using a least squares criterium was used to calculate the contributions of different protein secondary structures to the amide I region between 1630 and $1700 \mathrm{~cm}^{-1}$. The measured spectra were fitted with reference intensity profiles taken from literature. ${ }^{25,26}$ Profiles are available for four structures: two types of $\alpha$-helix conformations called helix A and $\mathrm{B}$, an undefined structure, and the $\beta$-sheet structure. After subtraction of the buffer background, described above, a straight line was drawn between 1500 and $1730 \mathrm{~cm}^{-1}$. The part of the spectrum between 1630 and $1700 \mathrm{~cm}^{-1}$ was normalized and fitted by the mentioned reference intensity profiles. 


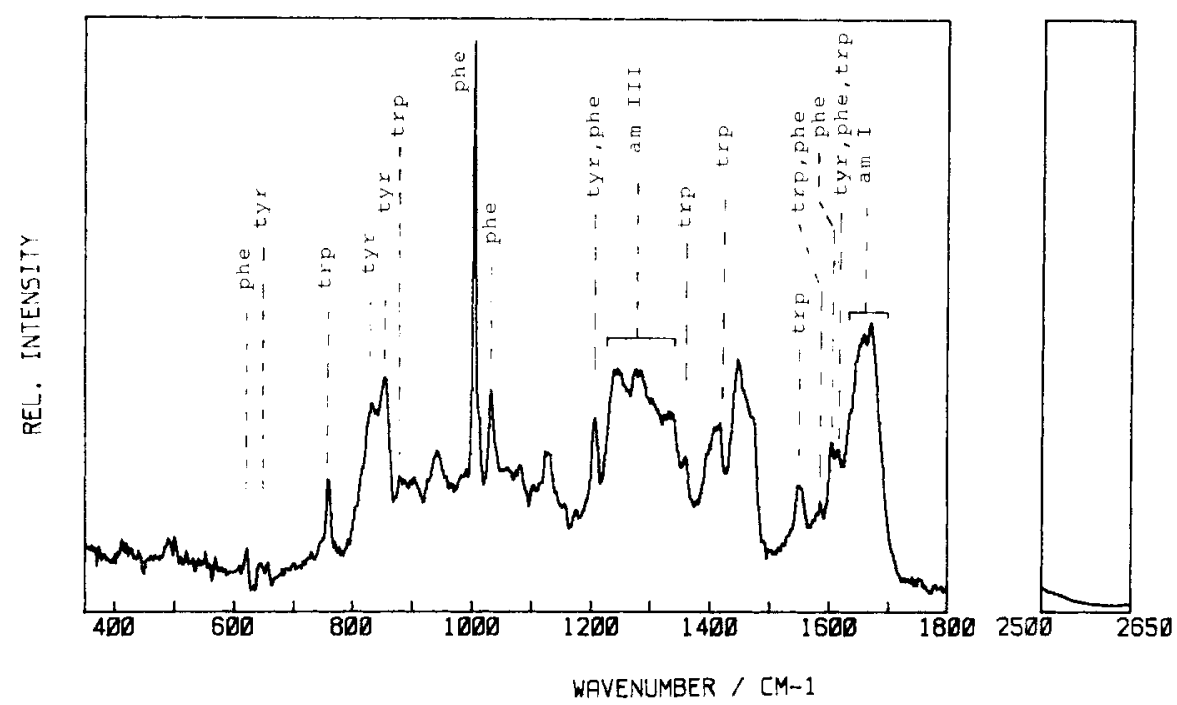

Fig. 2. Raman spectrum of gp32 from $550-1800 \mathrm{~cm}^{-1}$ and from $2500-2650 \mathrm{~cm}^{-1}$. The gp32 concentration: $10 \mathrm{mg} / \mathrm{mL}\left(\approx 2.8 \times 10^{-4} \mathrm{~mol} / \mathrm{L}\right)$; incident laser power: $900 \mathrm{~mW}$; slit widths: $4 \times 400 \mu \mathrm{m}$; spectral resolution: $3.2 \mathrm{~cm}^{-1}$; grating interval: $2 \mathrm{~cm}^{-1}$, measuring time per position: $4 \mathrm{~s}$; average of 4 runs, measured in a suprasil cuvette containing $80 \mu \mathrm{L}$ of solution.

\section{RESULTS}

Raman spectra of the free protein and of the protein complexed with nucleotides were measured. In the following sections we present some spectral details. Rather than giving all spectra, we draw attention to only some features.

\section{The gp32}

Earlier work describing Raman spectroscopic investigations of proteins ${ }^{27,28}$ discovered that the strongest contributions to the spectrum are due to the aromatic residues, i.e., tyrosine, tryptophan, and phenylalanine. Also, vibrations originating in the backbone, and in particular in the amide group, of the protein can be clearly resolved. In Fig. 2 the spectrum of gp32 is presented. Table I gives the assignments according to Refs. 24, 27 and 29-31. We measured gp32 at different concentrations to detect influences of the state of aggregation. ${ }^{7}$ Two phenomena are apparent. In the first place no sulfhydryl (SH-) stretch vibration, expected between $2560-2586 \mathrm{~cm}^{-1}$, can be detected in spite of the fact that even at the lowest concentration $(1 \mathrm{mg} / \mathrm{mL}$ protein) the detection limit should have been exceeded by a factor of 2 . At this concentration the threshold for the formation of gp32 multimeres $(0.1 \mathrm{mg} / \mathrm{mL})$ is still exceeded, however. It also is well known, ${ }^{5,6,17}$ and confirmed by our measurements, that no disulfur bridges, which can be expected between $500-550 \mathrm{~cm}^{-1}$ in the Raman spectrum, are present in gp32.

In the second place, a change in the ratio of the intensities of the tyrosine doublet, $I(854 / 830)$, can be observed. In Fig. 3(A and B) the protein concentration increases from 10 to $40 \mathrm{mg} / \mathrm{mL}$. This change can be explained ${ }^{32}$ as a change in the hydrogen-bonding conditions of (a part of) the tyrosine 
INTERACTION BETWEEN NUCLEOTIDES AND gp32

TABLE I

Position of the Raman bands in the Spectrum of $g \mathrm{p} 32^{\mathrm{a}}$

\begin{tabular}{|c|c|c|}
\hline $\mathrm{cm}^{-1}$ & Vibration Due to & Reference \\
\hline 414 & $\alpha$-Helix, Val, skeletal & 29 \\
\hline 490 & Skeletal: Val, Gly & 29 \\
\hline 622 & Phe & 29 \\
\hline 644 & Tyr & 29 \\
\hline 660 & C-S stretch Cys & 31 \\
\hline 700 & C-S stretch Met & 24,29 \\
\hline 730 & C-S stretch Met & 27 \\
\hline 744 & Ile, Ans. also Thr, Val & 30 \\
\hline 760 & Trp, Val & 29,30 \\
\hline 804 & Asn & 30 \\
\hline 812 & Ala, Asn & 30 \\
\hline 834 & Tyr; also Gly, Val & 29,30 \\
\hline 854 & Tyr & 29 \\
\hline 882 & Trp; also C-C stretch and Val & 30 \\
\hline 904 & Ala, C-C stretch & 29,30 \\
\hline 928 & Thr, Val & 29,30 \\
\hline 944 & Val, Leu ( $\mathrm{CH}_{3}$ symmetrical rock), Lys, C-C stretch & 29,30 \\
\hline 984 & Ile & 29 \\
\hline 1004 & Phe & 29 \\
\hline 1014 & Trp & 29 \\
\hline 1032 & Phe, Gly, Ser, Val & 29 \\
\hline 1058 & Lys, Glu, Ser & 29 \\
\hline 1081 & Glu, Thr, C-N stretch & 29,30 \\
\hline 1102 & Ala, C-N stretch & 29,30 \\
\hline 1116 & Unknown & \\
\hline 1128 & Val, Leu, Ile, Glu, Asp, Gly, C-N stretch & 29,30 \\
\hline 1154 & $\mathrm{C}-\mathrm{N}$ stretch & 30 \\
\hline 1176 & Val, Leu, $\left(\mathrm{CH}_{3}\right.$ asymmetrical rock) & 29 \\
\hline 1208 & Tyr, Phe & 27 \\
\hline $1220-1300$ & Amide III & 30 \\
\hline 1304 & $\mathrm{CH}_{2}$ twist/wag, C-H def & 29,30 \\
\hline 1314 & $\mathrm{CH}_{2}$ twist/wag, $\mathrm{C}_{\alpha}-\mathrm{H}$ def & 29 \\
\hline 1332 & $\mathrm{CH}_{2}$ twist/wag & 29 \\
\hline 1338 & Trp, C-H def & 29,30 \\
\hline 1358 & Trp, C-H def & 29,31 \\
\hline 1396 & $\mathrm{CH}_{3}$ symmetrical def, $\mathrm{CH}_{2}$ scissor & 29 \\
\hline 1416 & $\mathrm{CH}_{2}$ scissor & 29 \\
\hline 1425 & Trp & 30 \\
\hline 1448 & $\mathrm{CH}_{2}$ scissor & 29 \\
\hline 1460 & $\mathrm{CH}_{3}$ asymmetrical def & 29 \\
\hline 1468 & C-H def, $\mathrm{CH}_{2}$ symmetrical str, $\mathrm{CH}_{3}$ deg. str & 30 \\
\hline 1552 & $\operatorname{Trp}$ & 29 \\
\hline 1586 & Trp, Phe & 30 \\
\hline 1604 & Phe & 29 \\
\hline 1614 & Tyr, Phe, Trp & 30 \\
\hline $1630-1700$ & Amide I & 30 \\
\hline
\end{tabular}

The assignments are according to Refs. 24, 27, and 29-31, and references mentioned therein. 


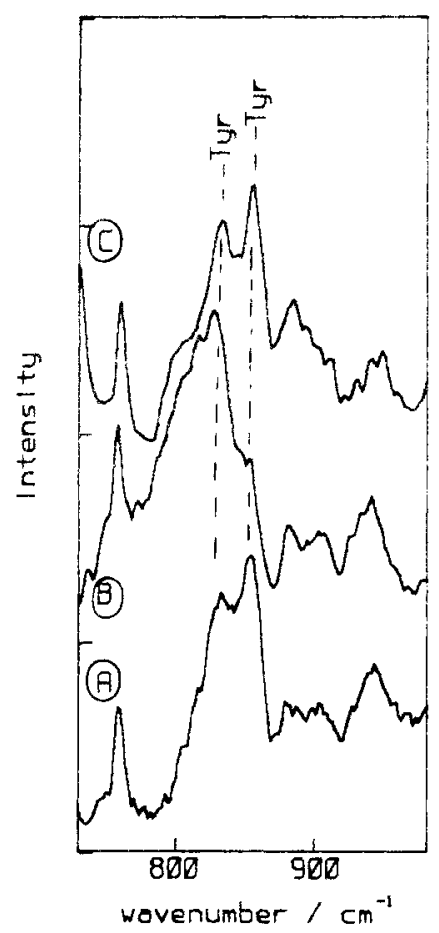

Fig. 3. A comparison of the region of tyrosine doublet (A) low concentration $(10 \mathrm{mg} / \mathrm{mL}),(B)$ high concentration $(40 \mathrm{mg} / \mathrm{mL}$ ) and (C) high concentration complexed with poly(rA). The "high-concentration" spectra were obtained in a square microcapillary with an internal dimension of $0.5 \mathrm{~mm}$.

residues present in the protein (see the discussion section). An investigation of the temperature dependence of the intensity ratio of the tyrosine lines at 830 and $854 \mathrm{~cm}^{-1}$ at low protein concentration revealed no changes, neither in the protein itself nor in complexes with nucleotides.

\section{gp32-Poly(oligo)nucleotide Complex}

From the comparison of the spectrum of gp32 complexed with poly(rA) at a high concentration [Fig. $3(\mathrm{C})$ ] with that of gp32 at high concentration [Fig. $3(\mathrm{~B})]$, a change in the intensity ratio $I(854 / 830)$ again can be observed. The interpretation of this change is presented in the discussion section. As was also observed in gp32 at both high and low concentrations, no SH-stretch vibration could be observed in the high concentration spectrum of gp32 with poly(rA).

We have compared difference spectra (see the materials and methods section) of the complex of gp32 with poly(rA) [Fig. 4(A)], poly(rC), poly(rU), poly(dA) [Fig. 4(B)], poly(dT) [Fig. 4(C)], (dA) 8 [Fig. 4(D)], and (dA) $)_{2}$ under conditions of low protein concentration $(\approx 10 \mathrm{mg} / \mathrm{mL})$. Several changes in the protein spectrum were observed. These changes did not depend on the kind of nucleotide, the type of sugar (either ribose or deoxyribose), or the length of the nucleotide chain. 


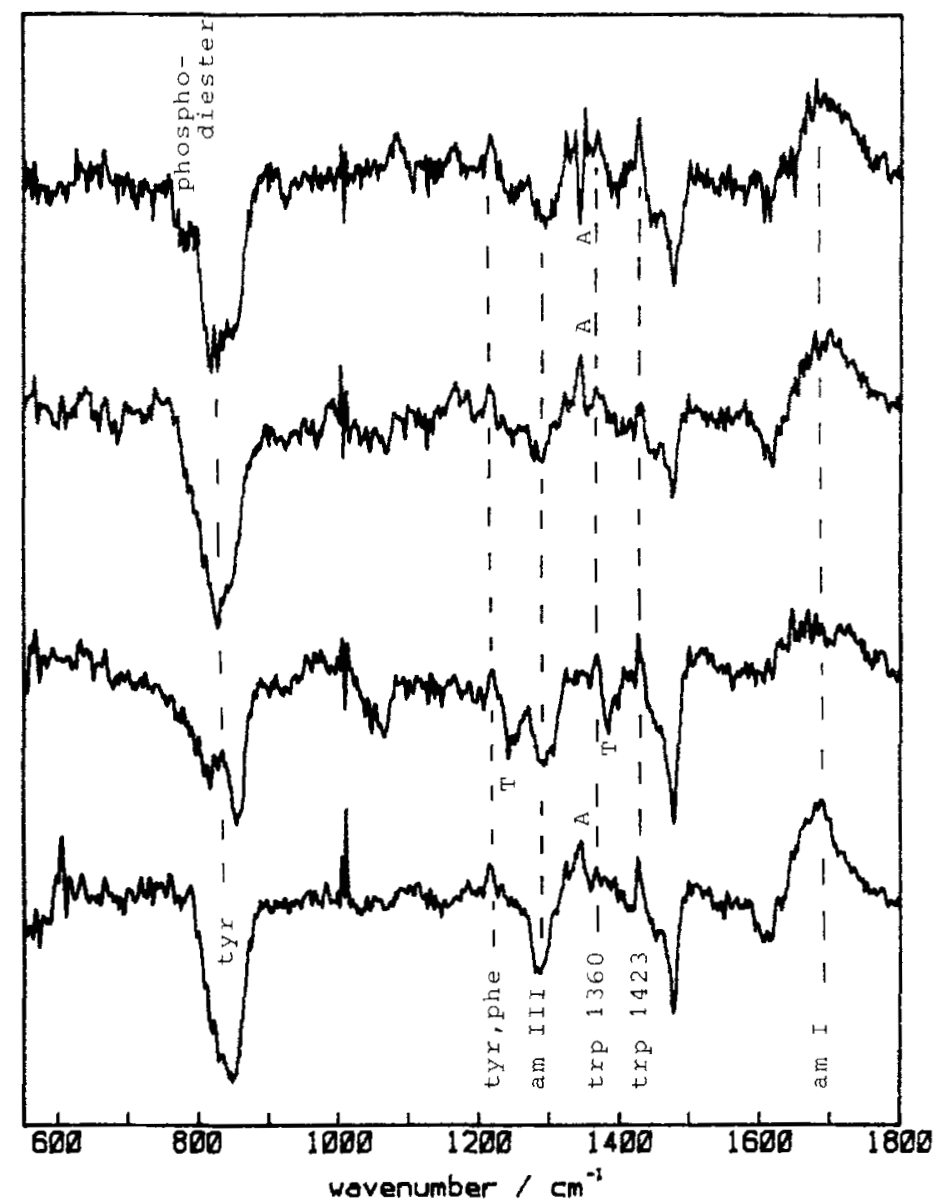

Fig. 4. Difference spectra (see text) for the formation of four poly(oligo)nucleotide-gp32 complexes. (A) gp32-poly(rA), (B) gp32-poly(dA), (C) gp32-poly(d'T), and (D) gp32-(dA) 8 Spectra of nucleotides and complexes were all obtained under the conditions mentioned in Fig. 1. The following abbreviations are used: T, thymine; A, adenine; Tyr, tyrosine; Trp, tryptophan; Am 1, amide I; and Am 3, amide III.

The following changes can be observed in the protein spectra upon complex formation:

1. At 1366 and $1423 \mathrm{~cm}^{-1}$ an increase in the intensity of tryptophan vibrations occurs.

2. A decrease of the intensity takes place at the position of the tyrosine doublet between $810-860 \mathrm{~cm}^{-1}$. The change, resulting from complex formation at low protein concentration, is different from that observed at high protein concentration.

3. An intensity increase occurs at $1208-1212 \mathrm{~cm}^{-1}$. At this position both phenylalanine and tyrosine contribute.

4. A decrease is observed in the intensity of the band between 1445-1470 $\mathrm{cm}^{-1}$ due to $\mathrm{CH}_{2}$-bending and $\mathrm{CH}_{3}$-bending motions. This decrease is larger at 

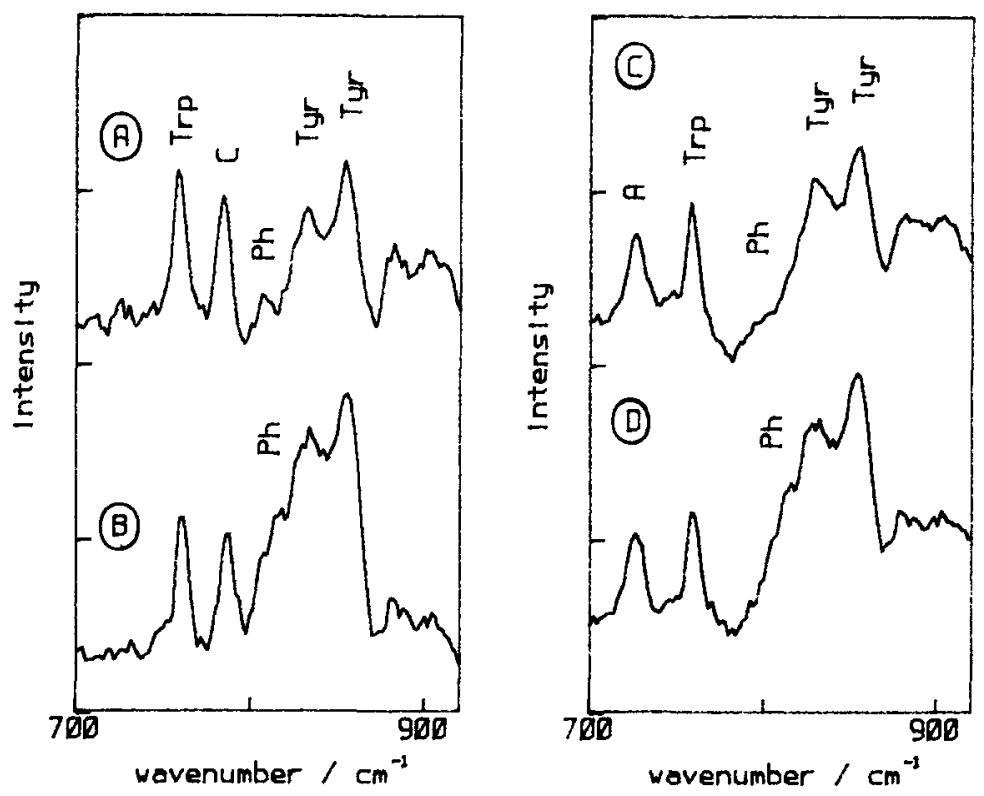

Fig. 5. A comparison of (A) the complex of poly $(\mathrm{rC})$ with gp32 with (B) the sum spectrum of poly $(\mathrm{rC})$ and $\mathrm{gp} 32$, and of $(\mathrm{C})$ the complex poly(rA) with gp32 with (D) the sum spectrum of poly(rA) and gp32. Observed in the spectra is the lack of change in the totally symmetric breathing mode of poly(rC) and poly(rA) and the change in the phosphodiester vibration. Abbreviations used as in Fig. 3. C, cytosine; Ph, phosphodiester.

the high-frequency side where $\mathrm{CH}_{3}$-bending motions are dominant than at the low-frequency side dominated by $\mathrm{CH}_{2}$-bending motions.

5. Changes in the secondary structure of the protein upon complex formation are indicated by an increase in intensity between $1660-1700 \mathrm{~cm}^{-1}$ in the amide $I$ band and a decrease in intensity at $1290 \mathrm{~cm}^{-1}$ in the amide III band. Based upon the general characteristics of amide I and amide III bands in proteins, an increase of $\beta$-sheet structure has occurred at the expense of other secondary structures present.

A discussion of these features is postponed to the discussion section.

\section{Nucleotides (Base Vibrations)}

It should be kept in mind that the changes measured in polynucleotide spectra depend both on the conformation of the polynucleotide in solution and on the conformation of the polynucleotide in the complex. Also, in the complex specific protein-nucleotide interactions may contribute to the observed spectra.

The totally symmetric ring breathing modes of adenine [in poly(rA) at 728 $\mathrm{cm}^{-1}$ ], cytosine [in poly(rC) at $784 \mathrm{~cm}^{-1}$ ], uracil [in poly $(\mathrm{rU})$ at $792 \mathrm{~cm}^{-1}$ ], and thymine [in poly $(\mathrm{d} T)$ at $750 \mathrm{~cm}^{-1}$ ] are neither shifted nor changed in intensity in the complex with gp32 [this can be observed from Fig. 5(A-D) for poly(rC) and poly(rA)]. 
In the single- and double-bond stretching region, however, some changes can be observed:

$$
\operatorname{Poly}(r A) / \operatorname{poly}(d A) /(d A)_{8}
$$

A positive shift to $1308 \mathrm{~cm}^{-1}$ is observed for the line at $1304 \mathrm{~cm}^{-1}$. This line can be attributed to ${ }^{33}$ the $\left(\mathrm{N}_{9} \mathrm{C}_{8}\right.$ stretch $+\mathrm{N}_{3} \mathrm{C}_{2}$ stretch $+\mathrm{C}_{8} \mathrm{H}$ bend $-\mathrm{C}_{2} \mathrm{H}$ bend) vibration. The intensity of the $\left(-\mathrm{N}_{7} \mathrm{C}_{5}\right.$ stretch $+\mathrm{C}_{8} \mathrm{~N}_{7}$ stretch) vibration at $1338 \mathrm{~cm}^{-1}$ in poly(rA), and $1346 \mathrm{~cm}^{-1}$ in poly $(\mathrm{dA})$ and $(\mathrm{dA})_{8}$, is influenced by protein binding. An increase in intensity takes place in the case of poly $(\mathrm{dA})$ and $(\mathrm{dA})_{8}$, while a decrease in intensity occurs for poly $(\mathrm{rA})$ [respectively, Fig. 4(B, D, and A)]. This suggests (see the discussion section) that the phosphate-sugar-base structures of poly(rA) and poly(dA) upon binding by gp32 become more alike than in the respective polynucleotides in solution but not completely the same (Fig. 6) and that binding causes a change in the phosphate-sugar-base conformers of both polynucleotides.

The interference of Raman lines of the amide III vibration with the $1304-\mathrm{cm}^{-1}$ line of poly $(\mathrm{rA})$ can be eliminated by deuteration of the samples. The amide III band then shifts ${ }^{34}$ from $1200-1300 \mathrm{~cm}^{-1}$ to $930-1030 \mathrm{~cm}^{-1}$. The results (Fig. 7) firmly establish the shift of the $1304-\mathrm{cm}^{-1}$ vibration and the decrease in the $1304-$ and $1338-\mathrm{cm}^{-1}$ vibration. The line of $1576 \mathrm{~cm}^{-1}$ has again been taken as an internal reference. ${ }^{24}$

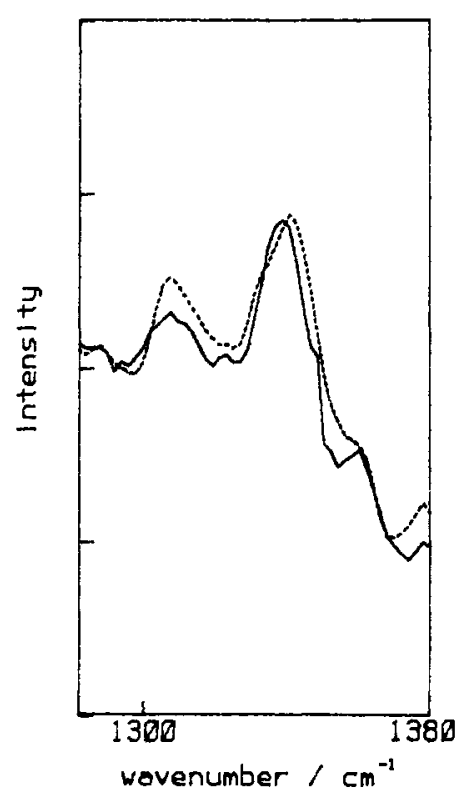

Fig. 6. A detail of the spectra of gp32-poly(rA) (I) and gp32-poly(dA) (II) showing the marker band for stacking interaction near $1304 \mathrm{~cm}^{-1}$ and the marker band for the phosphate-sugar-base structure near $1340 \mathrm{~cm}^{-1}$. The data reveal that the conformation of poly $(\mathrm{rA})$ and poly $(\mathrm{dA})$ in the complex are not completely the same. However, they are much more alike than in the free polynucleotides. 


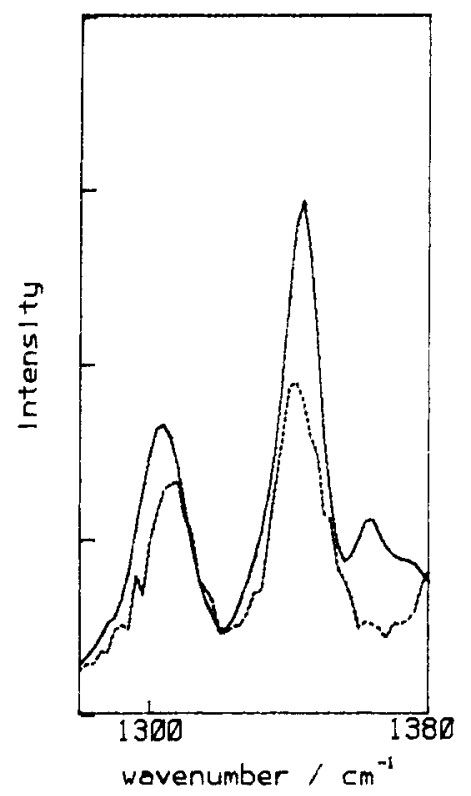

Fig. 7. A comparison of poly(rA) free in solution (solid line) and complexed by gp32 (dotted line) in deuterated samples. The complexed poly(rA) spectrum has been obtained by subtraction of the deuterated gp32 spectrum from the complex spectrum.

\section{$\operatorname{Poly}(r U)$}

Free poly(rU) does not have a stacked configuration under our measuring conditions. ${ }^{35}$ We measured a decrease in the intensity of the vibration at 1230 $\mathrm{cm}^{-1}$ upon complex formation. This is illustrated in Fig. 8, where a comparison is made of the complex spectrum with the sum spectrum.

This vibration is assigned to the $\left(\mathrm{C}_{5} \mathrm{C}_{6}\right.$ stretch $+\mathrm{N}_{1} \mathrm{H}$ bending $+\mathrm{C}_{5} \mathrm{H}$ bending) mode. ${ }^{36} \mathrm{It}$ is expected that the intensity of this line decreases when stacking interactions occur. ${ }^{35}$

\section{$\operatorname{Poly}(d T)$}

Like poly $(\mathrm{rU})$, poly $(\mathrm{dT})$ also lacks significant base stacking in solution. ${ }^{1}$ Binding of gp32 leads to a decreased intensity at $1378 \mathrm{~cm}^{-1}$ [Fig. 4(C)]. This vibration is assigned to the symmetrical $\mathrm{C}_{5}-\mathrm{CH}_{3}$ bending motion. ${ }^{37}$ It is not clear whether the intensity of this line is sensitive for stacking interactions. Also, the intensity of the (ring-stretch $+\mathrm{CH}$-bending) mode ${ }^{37}$ at $1240 \mathrm{~cm}^{-1}$ has decreased [Fig. 4(C)]. These changes can also be observed from Fig. 9, in which peak positions of thymine are indicated.

\section{Nucleotides (Phosphate Vibrations)}

Both poly $(\mathrm{rC})$ and poly $(\mathrm{rA})$ have a pronounced phosphodiester vibration respectively at 808 and $812 \mathrm{~cm}^{-1}$. In the complex a decreased contribution at these wavenumbers occurs [Fig. 5(A and B) for poly(rC) and Fig. 5(C and D) for poly(rA)]. In the case of poly(rA) a very weak and probably broadened line can be observed at $796 \mathrm{~cm}^{-1}$ [Fig. $\left.5(\mathrm{C})\right]$ while the stretch vibration of the 


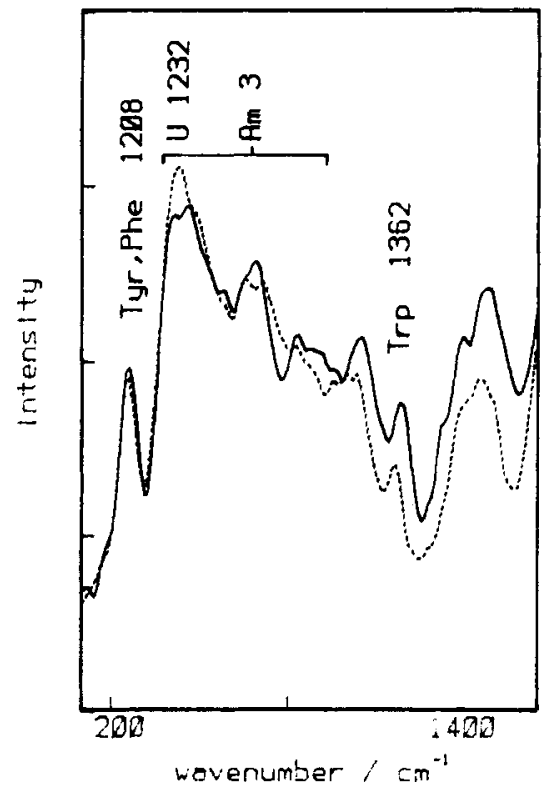

Fig. 8. The solid line is the complex spectrum of poly(rU) with gp32. The dotted line is the sum spectrum of poly(rU) and gp32. From the comparison it can be observed that, as a result of complex formation, a significant decrease in the intensity of the $1230-\mathrm{cm}^{-1}$ vibration of uracil takes place.

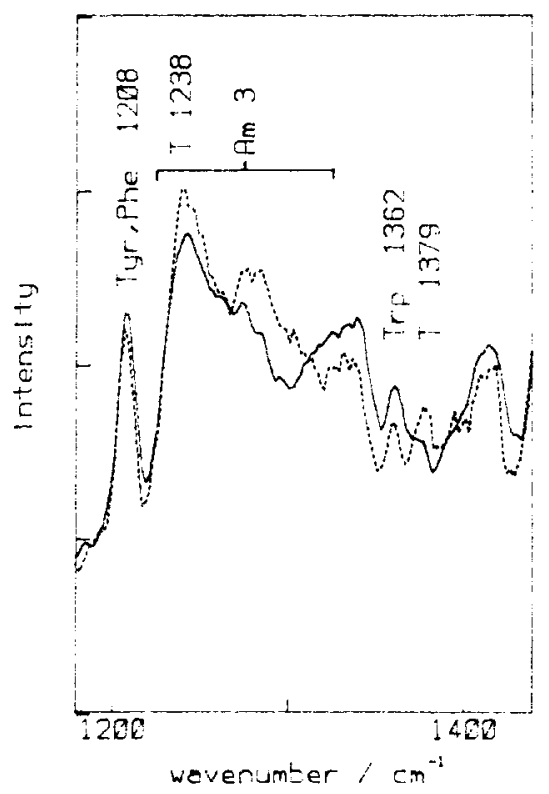

Fig. 9. The solid line is the complex spectrum of poly(dT) with gp32. The dotted line is the sum spectrum of poly $(\mathrm{d} T)$ and gp32. The complex formation results in a decrease of the intensity of thymine vibrations at 1240 and $1378 \mathrm{~cm}^{-1}$. 


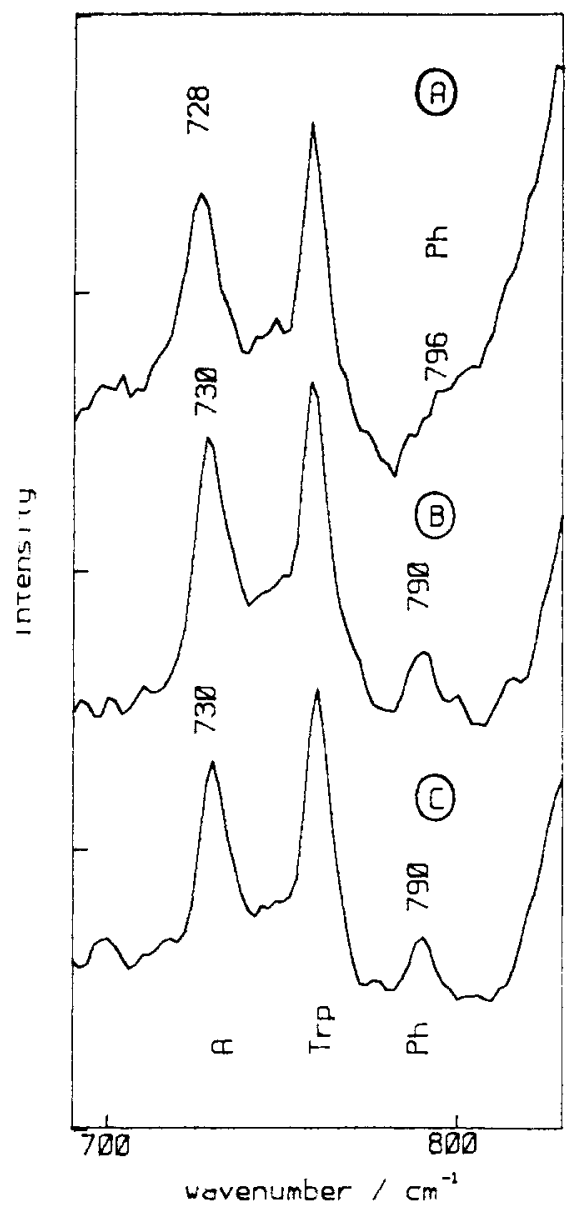

Fig. 10. A detail of the spectra of gp32-poly(rA) (A), gp32-poly(dA) (B), and gp32-(dA) $(\mathrm{C})$. The line due to the phosphodiester stretch at $790 \mathrm{~cm}^{-1}$ in the case of poly $(\mathrm{dA})$ and $(\mathrm{dA})_{8}$ is shown, and contrasted with the broad band at $796 \mathrm{~cm}^{-1}$ in case of poly(rA). Abbreviations as in Fig. 4.

(O-P-O) $)^{-}$group remains in the same place (not shown). The behavior of the phosphodiester vibration resembles that occurring upon a thermally induced order-disorder transition. ${ }^{38}$ In the case of poly $(\mathrm{dA})$ and $(\mathrm{dA})_{8}$ a band occurs at $790 \mathrm{~cm}^{-1}$ in both complex spectra (Fig. 10). This is identical to the position in uncomplexed poly $(\mathrm{dA})$ and $(\mathrm{dA})_{8}$. The position of this vibration in these compounds is also independent of the temperature over the range of $5-85^{\circ} \mathrm{C}$.

\section{DISCUSSION AND CONCLUSIONS}

\section{Amide Vibrations}

The Raman spectra provide evidence for changes in the secondary structure of the protein upon complex formation, as can be seen from the increase in intensity at $1660-1700 \mathrm{~cm}^{-1}$ in the amide I band and the decrease in the amide III region at $1290 \mathrm{~cm}^{-1}$ [see Fig. 4(A-D)]. The changes point to an 
TABLE II

Results of the Fit of the Amide 1 Region from $1630-1700 \mathrm{~cm}^{-1}$ to Reference Spectra $\mathrm{a}^{\mathrm{a}, \mathrm{b}}$

\begin{tabular}{llccc}
\hline & gp32 & gp32-Poly(rA) & gp32-Poly $(\mathrm{d} T)$ & gp32-(dA) \\
\hline$\alpha$-Helix A & 26 & 24.3 & 23.8 & 21.0 \\
$\alpha$-Helix B & 19.3 & 13.0 & 16.0 & 16.6 \\
$\alpha$-Helix (total) & 45.3 & 37.3 & 39.8 & 37.6 \\
$\beta$-Sheet & 39.5 & 44.6 & 46.1 & 48.1 \\
Undefined & 15.2 & 18.1 & 14.1 & 14.3 \\
\hline
\end{tabular}

"The numbers give percentages each particular secondary structure present in free gp32 and in gp32 in a complex with poly(rA), poly $\left(\mathrm{d}^{\prime} \mathrm{T}\right)$, and $(\mathrm{dA})_{8}$.

${ }^{\text {b }}$ The reference spectra from Refs. 25 and 26 are used. Two reference spectra for $\alpha$-helix-type secondary structure are used in order to be able to fit a variety of $\alpha$-helix band positions and bandshapes. These band positions may range from $1640-1654 \mathrm{~cm}^{-1}$. The peak positions of the used reference spectra are $\alpha$-helix A: $1640 \mathrm{~cm}^{-1} ; \alpha$-helix B: $1652 \mathrm{~cm}^{-1} ; \beta$-sheet: $1673 \mathrm{~cm}^{-1}$; and undefined: $1660 \mathrm{~cm}^{-1}$. The fundamental parameter for the amount of $\alpha$-helix present is the total amount of $\alpha$-helix. The reference spectra were obtained Refs. 25 and 26 from a set of proteins with a secondary structure known from x-ray crystallography. The Raman spectrum of proteins from this set could be accurately fitted by the obtained reference spectra. The results of the fit of Raman spectra correlated well with those obtained from crystallography. A correlation coefficient better than 0.96 was obtained. A correlation coefficient of 1 signifies an exact coincidence of Raman and $x$-ray results.

increased amount of undefined and/or $\beta$-sheet at the expense of $\alpha$-helix secondary structure. From these changes we can conclude that the protein adapts to the presence of the nucleotide. A change of the protein structure has been proposed ${ }^{5}$ to account for the increased accessibility of the $\mathrm{COOH}$-terminal domain in the polynucleotide binding mode. The increase of $\beta$-sheet structure that we observe (Table II) occurs irrespective of a binding in the polynucleotide or in the oligonucleotide binding mode. This is also neither dependent on the kind of nucleotide nor on the length of the nucleotide chain. So we are led to the conclusion that the binding of any nucleotide induces this change in the protein irrespective of the length of the nucleotide binding site being occupied. Therefore this effect is not a result of protein-protein interactions in the cooperative binding mode. The observation in Ref. 5 that no increased accessibility of the $\mathrm{COOH}$-terminal domain takes place in case of oligonucleotide binding rules out the possibility that it is merely a change in mobility of this domain.

The presence in gp32 of a large amount of aspartic acid, glutamic acid, asparagine, and glutamine allows us to propose that at least part of the changes in the amide I band (predominantly those at the high-frequency side) arises from alterations in the side bands of these amino acids upon nucleotide binding. Because there is no indication that changes in the amino acids may also affect the region around $1290 \mathrm{~cm}^{-1}$ in the amide III band it is reasonable to maintain that a change in the secondary structure does occur. With respect to the amide I band we cannot preclude, however, that both effects can be traced in the difference spectrum.

The results of the curve fitting of the amide I band (Table II) are quite different from those previously obtained from UV CD, ${ }^{8,12}$ which amounted to $22 \% \alpha$-helix, 26\% $\beta$-sheet, and 52\% unordered (undefined) conformation. The 


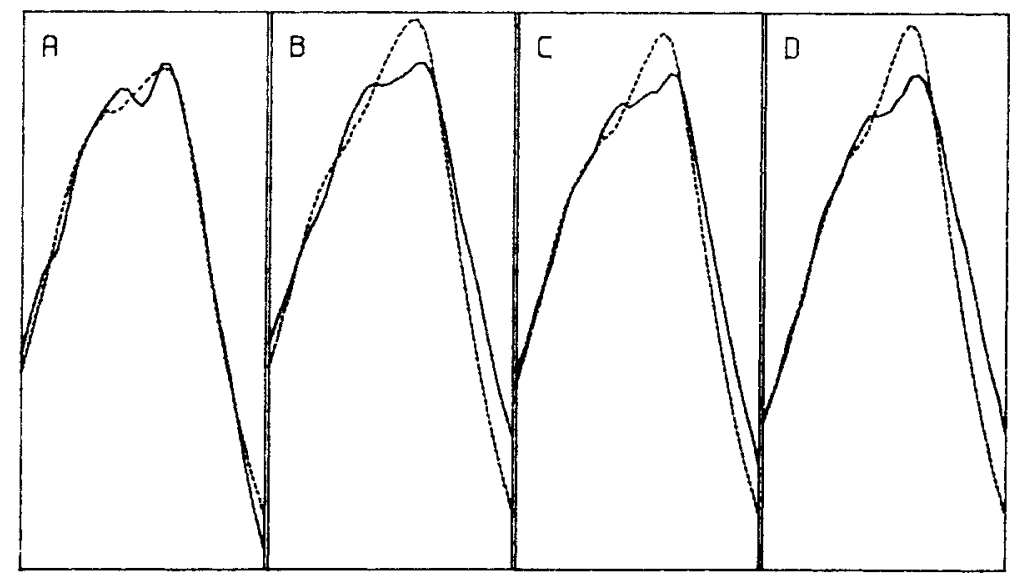

Fig. 11. An analysis of the amide I band from 1630 to $1700 \mathrm{~cm}^{-1}$. (A) $\mathrm{gp} 32$, (B) $\mathrm{gp} 32-\mathrm{poly}(\mathrm{rA})$, (C) gp32-poly(dT), and (D) gp32-(dA) . The solid line represents the measured spectrum. The dotted line is the result of the fit using the reference intensity profiles of four secondary structures determined by Alix and co-workers. ${ }^{25,26}$

results of our curve fitting (Table I) indicate the presence in the protein of $45 \% \alpha$-helix, $40 \% \beta$-sheet, and 15\% undefined structure. From Fig. 11 it can be seen that the fine structure in the gp32 spectrum could not be "ideally" fitted.

The solution to the discrepancy between the results of fitting procedures in Raman spectroscopy and CD must be sought in a refinement of the reference intensity profiles for both types of spectroscopy probably leading to a larger amount of distinct secondary structures, already proposed in literature. ${ }^{39}$

\section{Tryptophan}

An investigation of Bence-Jones protein ${ }^{22}$ and filamentous viruses ${ }^{29}$ has led to a correlation between spectral details related to tryptophan and its surroundings. It has been proposed ${ }^{22}$ that a high intensity ratio of the tryptophan vibrations at 879 and 759 is indicative of hydrophobic surroundings of the tryptophan residue. A clearly resolved and consequently sharp tryptophan vibration at $1359 \mathrm{~cm}^{-1}$ has also been proposed as an indicator for hydrophobic surroundings of the tryptophan residue. ${ }^{29,30,40}$

In gp32 the tryptophan lines at $759,879,1359$, and $1552 \mathrm{~cm}^{-1}$ are at identical positions as for tryptophan in aqeous solution. Neither the intensity of the $879 \mathrm{~cm}^{-1}$ nor the intensity of $1359 \mathrm{~cm}^{-1}$ indicates hydrophobic surroundings of tryptophan residues.

In the complexes with poly(oligo)nucleotides also, no change in the position of the tryptophan lines is observed. Therefore, from the line position no change in the surroundings of the residues can be concluded. Stacking interactions, however, do not necessarily lead to shifted frequencies. ${ }^{40}$ The difference spectra [Fig. 4(A-D)] indicate an increase in intensity at two positions where tryptophan lines contribute: $1358-1362$ and $1420-1425 \mathrm{~cm}^{-1}$. The change in the intensity of the vibration at $1360 \mathrm{~cm}^{-1}$ may indicate ${ }^{40,41}$ an increase of hydrophobicity of the surroundings. Also, the interaction of nucleophilic groups on the indole $\mathrm{N}-\mathrm{H}$ bond can lead to a corresponding effect. ${ }^{22}$ The 
involvement in the gp32-nucleotide interaction of the corresponding pyrrole ring system of the tryptophan molecules can be seen by virtue of the increase in intensity near $1422 \mathrm{~cm}^{-1}$. It is to this line as well as to the line at $879 \mathrm{~cm}^{-1}$ that the imidazole $\mathrm{N}$-H-bending motion contributes. ${ }^{42}$ In the previously mentioned study ${ }^{22}$ no change occurred in the line near $1422 \mathrm{~cm}^{-1}$. In our study, however, protein binding to a nucleotide lattice does not influence the intensity of the $879-\mathrm{cm}^{-1}$ vibration. This difference may be due to the fact that the $879-\mathrm{cm}^{-1}$ vibration is more connected to the benzenelike part of the molecule while the $1422-\mathrm{cm}^{-1}$ line is connected to a stretch motion of the pyrrole ring system. We therefore conclude that an interaction of tryptophan with the nucleotide takes place via the pyrrole ring.

\section{Tyrosine}

A region of particular interest in protein spectra is the region between 800 and $870 \mathrm{~cm}^{-1}$, because of the occurrence of two lines due to tyrosine. The relative intensity of these lines depends on the degree of hydrogen bonding to the phenolic hydroxyl group. Hydrogen bonding influences the electron density of the phenolic hydroxyl group, thereby changing the relative position of a symmetric ring breathing mode $\left(\nu_{1 \mathrm{a}}\right)$ and a nonplanar ring vibration $\left(\nu_{16 \mathrm{a}}\right){ }^{32}$

The relative intensity of the doublet is related because of a Fermi resonance between the fundamental of the $\nu_{1 a}$ vibration and the first overtone of the $\nu_{16 \mathrm{a}}$ vibration. Therefore it follows that the relative intensity can be used as a measure of the hydrogen-bonding interactions of the phenolic OH group. An empirical relationship has been established. ${ }^{32}$ Using the intensity ratios presented in Ref. 32 for different types of hydrogen-bonding interactions, the amount of tyrosine residues for which the surroundings change when the protein concentration increases (Fig. 3) can be calculated. It is thereby assumed that no ionized species are present, (the $\mathrm{pH}$ being 7.5 ) and that no phenolic hydroxyl group acts as an acceptor of strong hydrogen bonds, a situation that occurs, for instance, in solid L-tyrosine $\cdot \mathrm{HCl}$. From such an analysis it follows that, for gp32 at low concentration, all eight tyrosine residues are involved in hydrogen bond donating or accepting interactions of moderate strength, whereas at high concentration a change in 4-6 tyrosine residues resulting from coordination by strong hydrogen-bond acceptors is noticed (see Fig. 3). This number of residues is in reasonable agreement with the observations from $\mathrm{nmr}$ spectroscopy ${ }^{18}$ and from a chemical modification study, ${ }^{12}$ which show that five tyrosine residues are involved in binding of polynucleotides. These results can be explained in the following way: In gp32 carboxyl groups from aspartic and glutamic acid are present in abundance. At least part of these groups will be present at the protein-solution interface (C. Otto, (unpublished results) to take part in favorable ionic interactions with the polar solution. Together with the tendency of the protein to form multimer aggregates ${ }^{7}$ it is quite likely that some carboxyl groups from neighboring gp32 molecules modify the surroundings of tyrosine residues at high protein concentrations. This also indicates that the tyrosine residues are present at the outside of the protein molecule. The ability of polynucleotides [Fig. 3(C)] to shield the 4-6 tyrosine residues from the coordination by carboxyl groups makes it likely that the tyrosine residues are involved in the 
nucleotide interaction and also that the nucleotide binding site is at the surface of the gp32 molecule.

The difference spectra (from protein and protein-nucleotide complexes measured at a low concentration of $10 \mathrm{mg} / \mathrm{mL}$ ) also reveal an overall intensity decrease between $800-870 \mathrm{~cm}^{-1}$ together with small additional changes in shape and position of the tyrosine doublet. The peak positions of the doublet in the case of gp32 are 834 and $854 \mathrm{~cm}^{-1}$, while for gp32 in complex with poly(rA) the positions are shifted to 830 and $856 \mathrm{~cm}^{-1}$, respectively. These changes in position are most likely the result of the cumulative effect of complex formation on several tyrosine residues ( 8 residues are present), which cannot be separated in the Raman spectrum. The measured intensity decrease between 800 and $870 \mathrm{~cm}^{-1}$ occurs irrespective of the kind of binding mode, the type of nucleotide base, or the chain length, and therefore seems to correspond to a change in the protein as soon as binding occurs. The origin of this change is not, however, understood.

\section{$1208 \mathrm{~cm}^{-1}$}

The difference spectra reveal a positive contribution at $1208-1210 \mathrm{~cm}^{-1}$. Both phenylalanine and tyrosine residues contribute to the line at this position. Neither can be excluded from being affected by polynucleotide binding. From amino acid spectra the contribution of each phenylalanine residue is estimated to be $2 \frac{1}{2}$ to $3 \%$ of the measured intensity. Many phenylalanines must be influenced by the binding to allow for a change of about 6-8\% in the protein spectrum. Each tyrosine residue contributes about 5-6\% so a smaller partial change than in the case of phenylalanine is necessary to account for the observed change.

Assuming that the surroundings of five tyrosine residues have changed in a similar manner, a change of $20-60 \%$ in the $1208-\mathrm{cm}^{-1}$ line of each of these five residues would explain the observed change.

\section{Methyl / Methylene-bending Modes}

A large number of methyl and methylene groups, respectively 136 and 375, are present in gp32. In the region between 1440 and $1480 \mathrm{~cm}^{-1}$, where these groups contribute, a decrease in intensity occurs when complex formation takes place. Again, the change seems independent of the kind of nucleotide with which binding occurs and seems higher at the high wavenumber side of the band where methylene-bending contributions dominate the methyl-bending mode. The intensity decrease in this region is still quite puzzling. The many amino acids possibly involved hamper a further interpretation.

\section{Sulfhydryl Groups}

The gp32 contains four cysteine residues. We have tried to detect the strong SH-stretch vibration $\left(\approx 2575 \mathrm{~cm}^{-1}\right)$ at concentrations as low as $1 \mathrm{mg} / \mathrm{mL}$ gp32. No signal was obtained, while the SH concentration should still be a factor of 2 above the detection limit. At this concentration we are still a factor of 10 above the threshold for aggregation, which is roughly at $0.1 \mathrm{mg} / \mathrm{mL}{ }^{7}$ The explanation may be similar to that for the changes observed for the 
tyrosine residues. Coordination of the sulfhydryl groups by carboxyl or other groups may be responsible for the absence of a SH-stretch vibration.

That the supposed coordination of the $\mathrm{SH}$ groups still exists when no such effect can be measured for the tyrosine residues may be explained by the acidic strength of the different groups, i.e., $\mathrm{SH}$ : $\mathrm{pK}_{\mathrm{z}}=8.3$; Phenolic-OH: $\mathrm{pK}_{\mathrm{z}}=10.1 .^{35}$

Also, because no protein concentration dependence of the $\mathrm{SH}$ vibration has been observed, the possibility that the $\mathrm{SH}$ groups are coordinated by groups of the same protein molecule to which the SH groups belong cannot be neglected.

That no change in $\mathrm{SH}$ coordination is found upon polynucleotide binding is the more surprising since three of the four cysteine residues are found between a more or less regular array of six tyrosine residues in the linear amino acid sequence. ${ }^{17}$ This array may be involved in nucleotide binding.

\section{Polynucleotides}

When comparing the Raman spectra of single-stranded polynucleotides with those complexed by proteins we must realize that several distinct interactions may influence the relative intensity of the base vibrations. In the first place, there is the possibility that hydrogen bonding influences the intensity of base vibrations. ${ }^{43}$ Protein subunits may, for instance, form hydrogen bonds with those positions on the base that are involved in hydrogenbonding interactions in double-stranded nucleotides. In the second place, the protein may induce a certain type of sugar puckering with either syn or anti conformation of the base, thereby giving rise to a special phosphatesugar-base conformer. This conformation does not necessarily have to be a conformation known from the investigations of double-stranded structures. ${ }^{44,45}$ In the third place, interactions between the electron clouds of (partially) stacked bases also determine the measured relative intensity. The protein may influence these stacking interactions in several ways. We will return to this point later. It is clear that with Raman spectra alone these possible causes of the change of the relative intensities cannot be clearly distinguished from each other.

When the spectra of the uncomplexed single-stranded poly(rA) and single-stranded poly $(\mathrm{dA})$ are observed under the same conditions, the intensity of the band near $1340 \mathrm{~cm}^{-1}$ is larger in poly $(\mathrm{rA})$ than in poly $(\mathrm{dA})$. Furthermore, the position of the $\left(\mathrm{N}_{9} \mathrm{C}_{8}\right.$ stretch $+\mathrm{N}_{3} \mathrm{C}_{2}$ stretch $+\mathrm{C}_{8} \mathrm{H}$ bend $\mathrm{C}_{2} \mathrm{H}$ bend) vibration is $1304 \mathrm{~cm}^{-1}$ in poly $(\mathrm{rA})$ and $1308 \mathrm{~cm}^{-1}$ in poly $(\mathrm{dA})$. The peak height of this band is larger in poly $(\mathrm{dA})$ than in poly $(\mathrm{rA})$. These spectral differences are due to the second and third type of interaction. The sugar puckering in the case of poly(rA) is $\mathrm{C}_{3}^{\prime}$-endo while it is $\mathrm{C}_{2}^{\prime}$-endo in the case of poly $(\mathrm{dA})$. The orientation of the base is "anti" in both cases. [For a definition of the types of puckering and the anti ( syn) conformation, see for instance, Ref. 46.] The degree of base stacking of free polynucleotides can be influenced by changing the temperature of the solution. At $85^{\circ} \mathrm{C}$ both poly $(\mathrm{rA})$ and poly $(\mathrm{dA})$ are unstacked while their Raman spectra are not the same. This must be due to the conformation of the phosphate-(deoxy)ribose-base conformer. The most notable difference between $\operatorname{poly}(\mathrm{rA})$ and $\operatorname{poly}(\mathrm{dA})$ is, then, 
the intensity of the line near $1340 \mathrm{~cm}^{-1}$ attributed to the $\left(-\mathrm{N}_{7} \mathrm{C}_{5}\right.$ stretch + $\mathrm{C}_{8} \mathrm{~N}_{7}$ stretch) vibration. The intensity of this line decreases in poly(rA) and is independent of the temperature in poly $(\mathrm{dA})$. These observations indicate that this line is a marker for the structure of the phosphate-sugar-base conformation rather than for stacking interactions, because an intensity increase would have been expected if stacking interactions were the dominant interaction to describe the observed temperature-dependent intensity of these vibrations. ${ }^{35}$

The line at $\approx 1340 \mathrm{~cm}{ }^{1}$ can easily be observed in the complex. Binding of gp32 to the polynucleotide leads to a decrease in intensity for this line in the case of poly $(\mathrm{rA})$, while in case of poly $(\mathrm{dA})$ and $(\mathrm{dA})_{8}$ this line increases in intensity. We might think, from the similar influence that gp32 binding and temperature increases have on the intensity of the vibration near $1340 \mathrm{~cm}^{-1}$ in poly-rA, that binding of gp32 influences the structure of poly(rA) in a way similar to a temperature increase. This point of view is, however, not in agreement with what can be observed for gp32 binding and temperature increases in the case of poly $(\mathrm{dA})$ and $(\mathrm{dA})_{8}$. This behavior can be understood when we suppose that gp32 not merely causes an increase in base-base distance but also changes the phosphate-sugar-base conformation in case of poly(rA). Although the conformation of the nucleotides cannot be deduced from the data, it may be concluded that the structure of the phosphate--sugar--base conformation in poly $(\mathrm{rA})$ and poly $(\mathrm{dA})$ in the complex resemble each other more closely than in solution, but are not completely alike (Fig. 6). It may be that the large decrease in intensity in the $1340-\mathrm{cm}^{-1}$ line of poly(rA) complexed by gp32 (Fig. 7) is due to a change of sugar puckering from $\mathrm{C}_{3}^{\prime}$-endo to $\mathrm{C}_{2}^{\prime}$-endo. The increase in the intensity of this line in poly $(\mathrm{dA})$ [and $\left.(\mathrm{dA})_{8}\right]$, may then be the result of the greatly increased base-base distance in gp32-polynucleotide complexes. The remaining difference (Fig. 6) between the poly(rA) and poly(dA) Raman spectra may be a direct effect of the $\mathrm{OH}$ group on the ribose in the case of poly(rA). A comparison of free poly $(\mathrm{rA})$ and poly $(\mathrm{dA})$ at low and high temperature shows that the magnitude of the intensity change is largest for the vibration at 1304 $\mathrm{cm}^{-1}$ : the $\left(\mathrm{C}_{8} \mathrm{~N}_{9}\right.$ stretch $+\mathrm{C}_{2} \mathrm{~N}_{3}$ stretch) vibration. ${ }^{33,46}$ Thus this band can be regarded as a marker band for stacking interactions.

We can discern several ways in which a protein can influence stacking interactions of a polynucleotide: (1) by changing the base-base distance, which occurs in a gp32-polynucleotide complex ${ }^{9,10}$; and (2) by the introduction of aromatic amino acids like tyrosine, tryptophan, and phenylalanine between the nucleotide bases.

Following the stacking interactions by observation of the behavior of the $1304-\mathrm{cm}^{-1}$ vibration in poly(rA) (Fig. 7), it can be noted that the intensity of this vibration decreases upon binding by gp32. This behavior suggests that increased stacking interactions can occur in the complex. This is in contrast to what we would expect from the increase in the base-base distance that gp32 induces.

Another possibility, however, is the stacking of aromatic residues of the protein between the nucleotide base planes. When gp32 binds poly(rA), an increase of the base-base distance from 2.8 to $4.6 \AA^{14}$ takes place. Insertion of aromatic amino acids between the base planes would decrease the distance of an adenine base to the next aromatic residue from 2.8 to about $2.3 \AA$. So it is 
very well possible that we observe, in the decrease of the vibration at 1304 $\mathrm{cm}^{-1}$, the stacking of aromatic residues between the nucleotide bases leading to increased stacking interactions. This interaction may also be responsible for the decrease in intensity of the vibration at $1230 \mathrm{~cm}^{-1}$ in poly $(\mathrm{rU})$ and of the vibrations at 1240 and $1380 \mathrm{~cm}^{-1}$ in poly(dT).

In this section we relate some of our conclusions with those obtained from other spectroscopic studies. Nuclear magnetic resonance studies ${ }^{18}$ have previously revealed that tyrosine, phenylalanine, and one or more tryptophan residues are influenced by nucleotide binding, probably through stacking interactions. This must be compared with our finding that a stacking marker band in poly $(\mathrm{rA})$ indicates the increase of stacking interactions when poly $(\mathrm{rA})$ forms a complex with gp32.

We have observed, both through changes of the vibration spectrum of the backbone, as well as through an intensity increase of the $1336-\mathrm{cm}^{-1}$ band in poly $(\mathrm{rA})$ and an intensity decrease of the $1340-\mathrm{cm}^{-1}$ band in poly $(\mathrm{dA})$, that a change occurs in the phosphate-sugar-base conformer. Previous studies ${ }^{9,10}$ have established an elongation of the nucleotide backbone upon gp32 binding and this must be coupled to changes in the phosphate-sugar-base conformer.

The Raman spectra of uncomplexed poly(rA) and poly(dA) show large differences. In a complex with gp32, however, the spectra in the region of the phosphate-sugar-base conformer reveal a near coincidence of these spectra. This may be compared with the results from a CD study ${ }^{9}$ where a better similarity was also observed between poly $(\mathrm{rA})$ and poly $(\mathrm{dA})$ in the complexed state than in the free state. It can therefore be stated that the protein induces comparable secondary structures in these polynucleotides.

\section{SUMMARY OF CONCLUSIONS}

The following conclusions regarding the protein and the nucleotides can be drawn:

1. The measurements at high protein concentration reveal in an indirect way the involvement of 4-6 tyrosine residues in nucleotide binding.

2. All SH groups of gp32 are coordinated. No effect of protein concentration on the coordination can be measured above $1 \mathrm{mg} / \mathrm{mL}$.

3 . The nucleotide binding region of gp32 is situated on the solution surface of the protein.

4. The pyrrole ring system of one or more tryptophans is influenced by complex formation.

5. An intensity increase is observed for the vibration at $1208 \mathrm{~cm}^{-1}$. It is most likely attributed to a change in the tyrosine residues.

6. The secondary structure of gp32 changes. After complex formation an increased contribution of $\beta$-sheet structure is present. The conformation change does not depend on the length of the nucleotide chain.

7. The intensities of methyl- and methylene-bending modes are decreased as a result of complex formation.

8. The change in the phosphodiester-stretch vibration of poly $(\mathrm{rA})$ and poly $(\mathrm{rC})$ resembles the behavior upon order-disorder transition.

9. The phosphate-sugar-base structure in poly $(\mathrm{rA})$ and poly $(\mathrm{dA})$ changes when binding by gp32 occurs. 
10. With respect to the phosphate-sugar-base structure, it can be remarked that poly $(\mathrm{rA})$ and poly $(\mathrm{dA})$ resemble each other more closely when bound by gp32 than when free in solution. A sugar dependence of the conformation still exists.

11. Increased stacking interactions due to intercalation of tyrosines can explain the decrease in intensity in a stacking-marker band in poly(rA). Stacking interactions may also account for the decreased intensity of vibrations in poly $(\mathrm{rU})$ and poly $\left(\mathrm{d}^{\prime} \mathrm{T}\right)$.

This work was supported by the Netherlands Organization for the Advancement of Pure Research (Z.W.O.), The Netherlands Technology Foundation (S.T.W.), and the Pieter Langerhuizen Lambertuszoonfonds. Greatly appreciated is the assistance of Mrs. Ine Segers-Nolten in the preparation of the samples.

\section{References}

1. Coleman, J. E. \& Oakley, J. L. (1980) CRC Crit. Rev. Biochem. X, 247-289.

2. Alberts, B. M. \& Frey, L. (1970) Nature 227, 1313-1318.

3. von Hippel, P. H. \& McGhee, J. D. (1974) J. Mol. Biol. 86, 469-489.

4. Kowalczykowski, S. C., Lonberg, N., Newport, J. W. \& von Hippel, P. H. (1981) J. Mol. Biol. 145, 75-104.

5. Williams, K. R. \& Konigsberg, W. (1978) J. Biol. Chem, 253, 2463-2470.

6. Hosoda, J. \& Moise, H. (1978) J. Biol. Chem. 253, 7547-7555.

7. Carroll, R. B., Neet, K. \& Goldthwait, D. A. (1975) J. Mol. Biol. 91, 275-291.

8. Greve, J., Maestre, M. F., Moise, H. \& Hosoda, J. (1978) Biochemistry X, 887-893.

9. Scheerhagen, M. A., Blok, J. \& van Grondelle, R. (1985) J. Biomol. Struc. Dynamics 2, 821-829.

10. Delius, H., Mantell, N. J. \& Alberts, B. (1972) J. Mol. Biol. 67, 341-350.

11. Kelly, R., Jensen, D. \& von Hippel, P. H. (1976) J. Biol. Chem. 251, 7240-7250.

12. Anderson, R. A. \& Coleman, J. E. (1975) Biochemistry 14, 5485-5491.

13. Newport, J. W., Lonberg, N., Kowalczykowski, S. C. \& von Hippel, P. H. (1981) J. Mol. Biol. 145, 105-121.

14. Scheerhagen, M. A. (1986) Ph.D. thesis, Free University, Amsterdam.

15. Bobst, A. M., Langemeier, P. W., Warwick-Koochacki, P. E., Bobst, E. V. \& Ireland, J. C. (1982) J. Biol. Chem. 257, 6184-6193.

16. Jensen, D. E., Kelly, R. C. \& von Hippel, P. H. (1976) J. Biol. Chem. 251, 7215-7228.

17. Williams, K. R., Lopresti, M. B., Setoguchi, M. \& Konigsberg, W. H. (1980) Proc. Natl. Acad. Sci. USA 77, 4614-4617.

18. Prigodich, R. V., Casas-Finet, J., Williams, K. R., Konigsberg, W. H. \& Coleman, J. E. (1984) Biochemistry 23, 522-529.

19. Toulme, J. J., le Doan, T. \& Helene, C. (1984) Biochemistry 23, 1195-1201.

20. Inman, R. B. (1964) J. Mol. Biol. 9, 624-637.

21. Gray, D. M. \& Bollum, F. J. (1974) Biopolymers 13, 2087-2102.

22. Kitagawa, T., Azuma, T. \& Hamaguchi, K. (1979) Biopolymers 18, 451-465.

23. Fish, S. R., Hartman, K. A., Stubbs, G. J. \& Thomas, G. J., Jr. (1980) Biochemistry 20, $7449-7457$.

24. Prescott, B., Steinmetz, W. \& Thomas, G. J., Jr. (1984) Biopolymers 23, 235-256.

25. Berjot, M., Marx, J. \&, A. J. P. (1985) J. Ramanspectrosc., submitted.

26. Alix, A. J. P., Berjot, M. \& Marx, J. (1985) in Spectroscopy of Biological Molecules, Alix,

A. J. P., Bernard, L. \& Manfait, M., Eds., pp. 149-154.

27. Lord, R. C. \& Yu, N.-T (1970) J. Mol. Biol. 50, 509-524.

28. Lord, R. C. \& Yu, N.-T. (1970) J. Mol. Biol. 51, $203-213$.

29. Thomas, G. J., Jr., Prescott, B. \& Day, L. A. (1983) J. Mol. Biol. 165, 321-356.

30. Thomas, G. J., Jr., Prescott, B., McDonald-Ordzie, P. E. \& Hartman, K. A. (1976) J. Mol. Biol. 102, 103-124.

31. Chen, M. C., Lord, R. C. \& Mendelsohn, R. (1974) J. Am. Chem. Soc. 96, 3038-3042. 
32. Siamwiza, M. N., Lord, R. C., Chen, M. C., Takamatsu, T., Harada, I., Matsuura, H. \& Shimanouchi, T. (1975) Biochemistry 14, 4870-4876.

33. Tsuboi, M., Takahashi, S. \& Harada, I. (1973) in Physico-Chemical Properties of Nucleic Acids, Vol. 2, Duchesne, J., Ed., Academic Press, New York,

34. Williams, R. W., Cutrera, T., Dunker, A. K. \& Peticolas, W. L. (1980) FEBS Lett. 115, 306-308.

35. Small, E. W. \& Peticolas, W. L. (1971) Biopolymers 10, 1377-1416.

36. Chin, S., Scott, I., Szczepaniak, K. \& Person, W. B. (1984) J. Am. Chem. Soc. 103, 3415-3422.

37. Susi, H. \& Ard, J. S. (1974) Spectrochim. Acta 30A, 1843-1853.

38. Thomas, G. J., Jr. \& Hartman, K. A. (1973) Biochim. Biophys. Acta 312, 311-322.

39. Byler, D. M. \& Susi, H. (1986) Biopolymers 25, 469-487.

40. Thomas, G. J., Jr. \& Kyogoku, Y. (1977) in Infrared and RamanSpectroscopy, Part C, Brame, E. G., Jr. \& Grasselli, J. G., Eds., Dekker, New York.

41. Yu, N.-T. (1974) J. Am. Chem. Soc. 96, 4664-4668.

42. Hirakawa, A. Y., Nishimura, Y., Matsumoto, T., Nakanishi, M. \& Tsuboi, M. (1978) J. Ramanspectrosc. 7, 282-287.

43. Hartman, K. A., Lord, R. C. \& Thomas, G. J., Jr. (1973) in Phisico-Chemical Properties of Nucleic Acids, Vol. 2, Duchesne, J., Ed., Academic Press, New York.

44. Pohl, F. M., Ranade, A. \& Stockburger, M. (1973) Biochym. Biophys. Acta 335, 85-92.

45. Thomas, G. J., Jr. \& Benevides, J. M. (1985) Biopolymers 24, 1101-1105.

46. Ts'O, P. O. P. (1974) in Basic Principles in Nucleic Acid Chemistry, Vol. 1, Ts'O, P. O. P., Ed., Academic Press, New York.

47. Chen, M. C., Lord, R. C. \& Mendelsohn, R. (1973) Biochym. Biophys. Acta 328, 252-260.

48. Lehninger, A. L. (1976) in Biochemistry, 2nd ed., Worth Publishers Inc.

49. Hirakawa, A. Y., Okada, H., Sasagawa, S. \& Tsuboi, M. (1985) Spectrochim. Acta, 41A, $(1 / 2), 209-216$.

Received September 3, 1986

Accepted March 24, 1987 